Article

\title{
Necessity of Assessing Biological Exposure to Arsenic Species by Two Representative Analytical Methods
}

\author{
Jeong-Wook Seo ${ }^{1}$ and Young-Seoub Hong ${ }^{1,2, *}$ \\ 1 Environmental Health Center, Dong-A University, Busan 49201, Korea; jwseo@dau.ac.kr \\ 2 Department of Preventive Medicine, Dong-A University, Busan 49201, Korea \\ * Correspondence: yshong@dau.ac.kr; Tel.: +82-51-240-2888
}

check for updates

Citation: Seo, J.-W.; Hong, Y.-S.

Necessity of Assessing Biological Exposure to Arsenic Species by Two Representative Analytical Methods. Toxics 2021, 9, 138. https://doi.org/ $10.3390 /$ toxics 9060138

Academic Editor:

Radu-Corneliu Duca

Received: 3 March 2021

Accepted: 8 June 2021

Published: 11 June 2021

Publisher's Note: MDPI stays neutral with regard to jurisdictional claims in published maps and institutional affiliations.

Copyright: (C) 2021 by the authors. Licensee MDPI, Basel, Switzerland. This article is an open access article distributed under the terms and conditions of the Creative Commons Attribution (CC BY) license (https:// creativecommons.org/licenses/by/ $4.0 /)$.

\begin{abstract}
Arsenic (As) exists as highly toxic chemical species. Chronic exposure to its inorganic form can cause multiple organ failure and skin cancer in humans, warranting the need to determine the toxicity of each chemical species. This study evaluated the proportions of exposure to four chemical species of As (cAs), namely arsenite (AsIII), arsenate (AsV), monomethylarsinic acid (MMA), and dimethylarsenic acid (DMA), and it confirmed the necessity of evaluating biological exposure to cAs. Urine samples were collected from 457 subjects residing near 103 abandoned metal mines. Hydride generation atomic absorption spectroscopy (HG-AAS) was performed to measure the combined concentration of four cAs (hAs AAS). High-performance liquid chromatography and inductively coupled plasma-mass spectrometry (HPLC-ICP-MS) were performed to determine the concentrations of the individual cAs and the sum of the four cAs (hAs $\mathrm{SICP}_{\mathrm{ICP}}$. The proportions of AsV and MMA were relatively higher in the low-hAs $\mathrm{s}_{\mathrm{ICP}}$ concentration section. These findings suggest that $\mathrm{hAs}$ AAS, which is mainly used for its cost-efficiency, is limited for evaluating exposure. Though hAs AAS was found to exist in a low concentration, highly toxic AsV and MMA could be observed in high concentrations. Therefore, HPLC-ICP-MS is recommended for assessing cAs in environmentally vulnerable areas such as abandoned metal mines.
\end{abstract}

Keywords: arsenate; arsenite; atomic absorption spectroscopy; biological exposure assessment; dimethylarsenic acid; inductively coupled plasma mass spectrometry; monomethylarsinic acid

\section{Introduction}

In the environment, As occurs in various oxidation states and in both inorganic and organic forms. The chemical species of arsenic (cAs) differ in terms of their toxicity and health effects. In general, inorganic arsenic (iAs) is more toxic than organic arsenic (oAs), and arsenite (AsIII) is more toxic than arsenate (AsV) [1]. A previous study reported that oAs in methylated metabolites such as monomethylarsinic acid (MMA) and dimethylarsenic acid (DMA) are nontoxic [2]. In contrast, other studies have suggested that monomethylarsonous acid (MMA (III)) is highly toxic [3,4]. Chronic exposure to iAs affects not only the skin but also the respiratory, gastrointestinal, cardiovascular, nervous, hepatic, endocrine, and hematopoietic systems [5]. Additionally, long-term iAs exposure may induce skin cancer [2].

Exposure to most As compounds occurs through drinking water and food intake [1]. Exposure may be a consequence of the natural occurrence of highly concentrated As in groundwater. Food is the second leading source of As intake [6]. Exposure might result from the consumption of crops grown in As-contaminated soils and dust inhalation in polluted areas such as mines [1,7]. Occupational exposure can occur through the inhalation of dust or aerosols with high As levels [8,9].

Human As exposure has been assessed by measuring total arsenic (tAs) using inductively coupled plasma-mass spectrometry (ICP-MS) and/or hazardous arsenic species (hAs: inorganic-related As species-AsIII, AsV, MMA, and DMA) using hydride generation atomic absorption spectroscopy (HG-AAS). However, the importance of knowing 
the effects of cAs on health has been emphasized, and the assessment of exposure to the individual species is required. Korea's Environmental Health Act stipulates the duty of the epidemiological investigation and management in areas where environmental pollution is a concern. The Health Effects Survey of Abandoned Metal Mines (AMS: Abandoned Metal Mines Survey) has been carried out since 1996 as biomonitoring for abandoned metal mines, which are areas of concern for representative environmental pollution. AMS mainly evaluates human exposure to hazardous metals from abandoned metal mines, and individual follow-up management is carried out for subjects exposed to high concentrations. This includes the assessment of arsenic exposure due to contaminated drinking water and soil. Through the AMS, the concentration of hAs measured by HG-AAS (hAs AAS) was evaluated. In addition, AsIII, AsV, MMA, and DMA were quantitatively analyzed only when the $\mathrm{hAs}_{\mathrm{AAS}}$ was high using high-performance liquid chromatography and inductively coupled plasma-mass spectrometry (HPLC-ICP-MS), which required a high cost, and their sum, hAsicP, was evaluated.

In this study, we aimed to confirm the necessity of evaluating biological exposure to cAs. For this purpose, AMS data were used to confirm the characteristics and proportion of the exposure level to cAs. We also discussed the consistency and interchangeability of hAs AAS and hAs $\mathrm{ICP}_{\mathrm{ICP}}$ with AsIII, AsV, MMA, and DMA depending on the hAs $\mathrm{AAS}$ concentration.

\section{Materials and Methods}

\subsection{Study Population}

The Korean Ministry of the Environment (KMOE) reported data for general and specific investigations on the soil and water pollution levels of 857 abandoned metal mines during 1996-2005. A preliminary investigation was conducted on 358 abandoned metal mines with known risks of inducing health effects. The overall risk was quantified according to the results of the environmental pollution and impact assessments. First-level (08-11) and second-level (13-17) abandoned metal mines surveys (AMSs) were performed in the top $10 \%$ of 38 regions and in the top $10-40 \%$ of 103 mines, respectively (Figure 1 ). In the present study, second-level AMS data were used. A total of 4500 people were surveyed over 5 years in five regions, and standardized tools and guidelines were used. A questionnaire on subject residential areas and characteristics was conducted, and analyses of harmful metals, such as lead and cadmium in the blood and As in the urine, were performed. The hAs $\mathrm{AAS}_{\mathrm{AS}}$ concentrations were evaluated in all 4500 people. The top $10 \%$ or those with $>100 \mu \mathrm{g} / \mathrm{L}$ were defined as subjects with a high As exposure. In these subjects, cAs was measured using HPLC-ICP-MS. There were 457 subjects whose creatinine levels were within the normal range of $0.3-3.0 \mathrm{~g} / \mathrm{L}$, and they were selected as the final subjects for analysis [10,11].

\subsection{Sample Collection}

All procedures related to biological sample collection and heavy metal analysis were performed in accordance with the guidelines of the Korea National Institute of Environmental Research (KNIER) [12,13]. To prevent contamination, urine samples were collected only after the subjects had become familiar with the collection method. Ten milliliters of midstream urine was collected in a dedicated urine cup (PLC-03701 natural polypropylene jar with a 58-400 white polypropylene unlined cap 120 m; Qorpak, Bridgeville, PA, USA). The initial urine stream was discarded. Five-milliliter aliquots of the collected urine were placed in dedicated containers (229412 centrifuge tube, $15 \mathrm{~mL}$, polypropylene, CELLTREAT, Pepperell, MA, USA) and stored at $-80^{\circ} \mathrm{C}$.

\subsection{Arsenic Determined Using Hydride Generation Atomic Absorption Spectroscopy}

HG-AAS (inAAcle 900Z atomic absorption spectrometer/FIAS 100 flow injection for atomic spectroscopy system, PerkinElmer, Waltham, MA, USA) was used for quantitative hAs analysis. As a pre-reductant required for analysis, 10\% L-Cysteine (Sigma-Aldrich Corp., St. Louis, MO, USA) was used in $0.03 \mathrm{M} \mathrm{HCl}$, and $0.5 \% \mathrm{NaBH}_{4}$ in $0.05 \% \mathrm{NaOH}$ 
was used as a hydride reagent. Additionally, $0.03 \mathrm{M} \mathrm{HCl}$ was used as the carrier solution. Impurities were removed from the urine samples using a $0.22-\mu \mathrm{m}$ filter. The sample was diluted 10 times to $10 \mathrm{~mL}$ and measured after a 1:1 reaction with pre-reductant. Standard stock solution (Inorganic ventures, Christiansburg, VA, USA) samples were used to plot calibration curves (Inorganic ventures, Christiansburg, VA, USA). Standard materials (ClinChek urine control lyophilized for trace elements, Levels I and II, RECIPE Chemicals, Dessauerstraße, München, Germany) were used to confirm process reliability. The analysis library was accredited by the KNIER Quality Assurance Program.

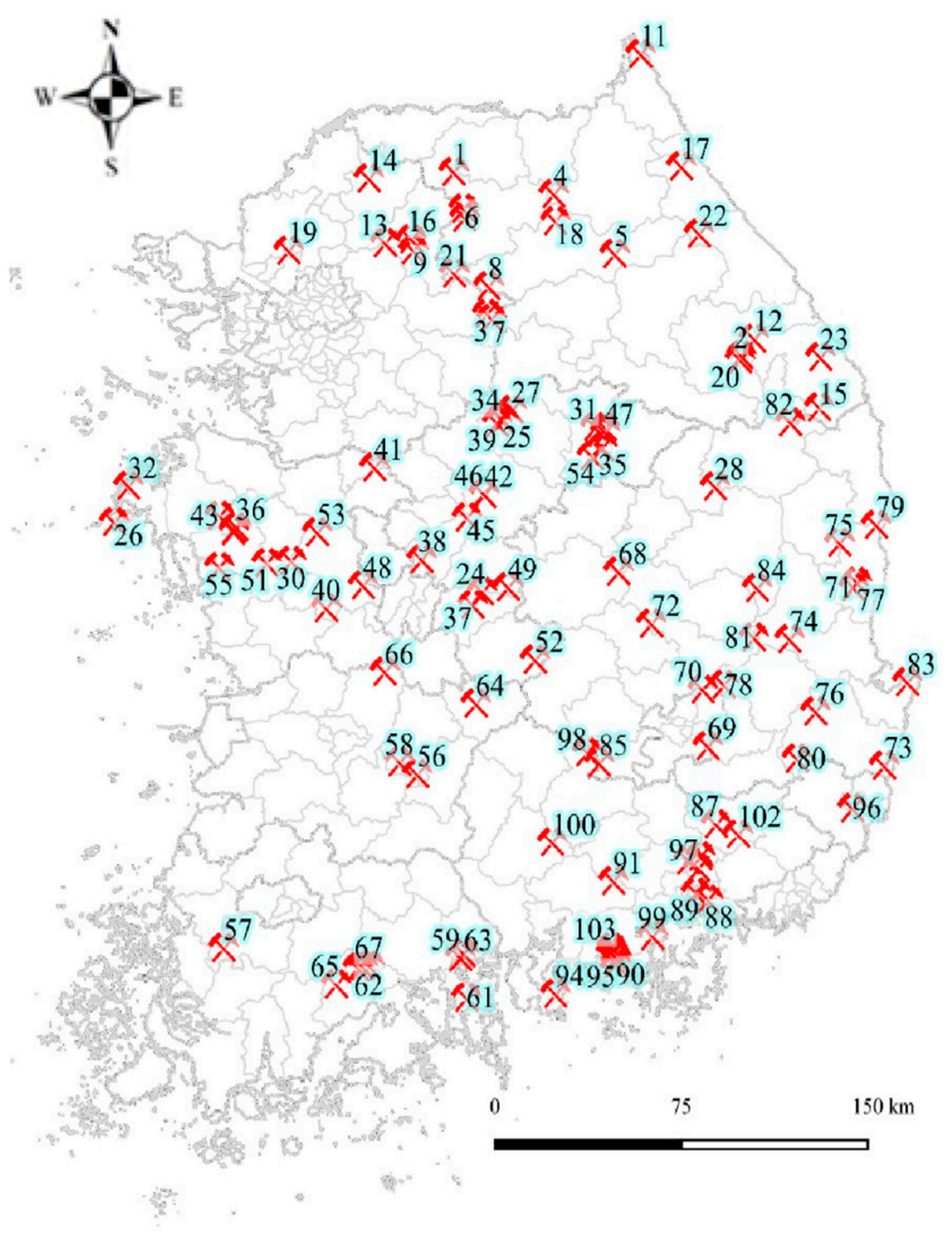

Figure 1. Location of the 103 abandoned metal mines.

2.4. Arsenic Speciation Determined Using High-Performance Liquid Chromatography with Inductively Coupled Plasma-Mass Spectrometry

To separate and quantify cAs, impurities were removed from urine samples using a $0.22-\mu \mathrm{m}$ filter, and the samples were then diluted with an appropriate amount of dextrose solution. As a mobile phase, $10 \mathrm{mM}$ ammonium carbonate $(99.99 \%), 10 \mathrm{mM}$ Trizma ${ }^{\circledR}$ base (99.9\%) (Sigma-Aldrich Corp., St. Louis, MO, USA), and $15 \mathrm{mM}$ ammonium sulfate (99.5\%) (Junsei chemical Co., Ltd., Chuo-ku, Tokyo, Japan) were used. HPLC-ICP-MS (Agilent Technologies 1260 series high-performance liquid chromatography/7700 series inductively 
coupled plasma-mass spectrometer, Agilent Technologies, Santa Clara, CA, USA) fitted with a Hamilton PRP X-100 column was used to quantitate AsIII, AsV, MMA, and DMA. Calibration curves were plotted using standard AsIII, AsV, MMA, and DMA (Sigma-Aldrich Corp., St. Louis, MO, USA), and their accuracy was verified using two reference standards (Standard Reference Material No. 2669, National Institute of Standards and Technology (NIST), Gaithersburg, MD, USA; Certified Reference Material No. 18, National Institute for Environmental Studies, Onogawa, Tsukuba, Japan). The analytical laboratory was accredited by the quality assurance program of the German External Quality Assessment Scheme (G-EQUAS) operated by Friedrich-Alexander University, Erlangen-Nuremberg, Germany [14].

\subsection{Statistical Analysis}

All data were analyzed using SASv. 9.4 (SAS Institute, Cary, NC, USA). Means and dispersion were estimated to confirm the distribution of urinary arsenic concentration (UAL: urine arsenic level) determined using HG-AAS and HPLC-ICP-MS. The concordance correlation coefficient (CCC) was calculated to evaluate consistency between the methods. For the proportion of cAs measured by HPLC-ICP-MS, the least square means (LSMs) were calculated after adjusting for the subject characteristics. A simple nonlinear model was used to estimate the proportions of cAs according to the UAL returned by HG-AAS. Goodness-of-fit was determined for the observed values. The significance level was set at below $5 \%$ for all statistics.

\subsection{Ethics Statement}

Participants were given fully explanations of the study purpose and procedure, and an agreement for the questionnaire and blood sample collections was secured from them. Personal information and specimen analyses were then provided to all participants. The present study was approved by the Chung-Ang University Institutional Review Board (IRB No. 1041078-201805-HRBR-103-01, approved on 26 June 2018).

\section{Results}

\subsection{Distribution of Urinary Arsenic Concentration}

Table 1 shows the UAL distribution of 457 samples analyzed using HG-AAS and HPLC-ICP-MS. One of the 103 abandoned metal mines showed very high As concentrations in potable tap water and groundwater. Hence, this area introduced an extreme value to the overall distribution, and the data were stratified for the estimation. The geometric means (GMs) (95\% confidence interval (CI)) of the UAL for each of the 102 mines were 0.12 (0.10-0.14), 0.34 (0.29-0.39), 0.92 (0.76-1.12), and 70.61 (65.78-75.81) $\mu \mathrm{g} / \mathrm{g}$-creatinine $(\mu \mathrm{g} / \mathrm{g}$-cr) for AsIII, AsV, MMA, and DMA, respectively. The UAL of hAs ICP or the sum of the four cAs associated with iAs (UAL ICP) was 77.05 (72.11-82.32) $\mu \mathrm{g} / \mathrm{g}$-cr. In contrast, the UAL of hAs $\mathrm{AAS}\left(\mathrm{UAL}_{\mathrm{AAS}}\right)$ was $55.14(50.76-59.91) \mu \mathrm{g} / \mathrm{g}$-cr. The single mine with As-contaminated drinking water showed 16.12 (6.12-42.46) and 5.30 (1.83-15.36) $\mu \mathrm{g} / \mathrm{g}$-cr for AsIII and AsV, respectively. The sum of AsIII and AsV was 31.44 (21.44-46.12) $\mu \mathrm{g} / \mathrm{g}$-cr, which was 50 times higher than the sum of that of the other 102 mines $(0.65$ $(0.56-0.75) \mu \mathrm{g} / \mathrm{g}$-cr). The values for MMA (20.06 (12.04-33.43) $\mu \mathrm{g} / \mathrm{g}$-cr) and DMA (183.60 $(146.52-230.07) \mu \mathrm{g} / \mathrm{g}$-cr) were $\sim 30$ times higher than the sum of those in the 102 mines. The arithmetic mean (AM) \pm standard deviation (SD) of the proportion of chemical species was the highest for DMA (91.74 $\pm 9.67 \%)$, followed by MMA $(4.24 \pm 4.40 \%)$, AsV (2.82 $\pm 6.43 \%)$, and AsIII (1.21 $\pm 2.89 \%)$. 
Table 1. Distribution of urinary arsenic concentration in residents living near abandoned metal mines.

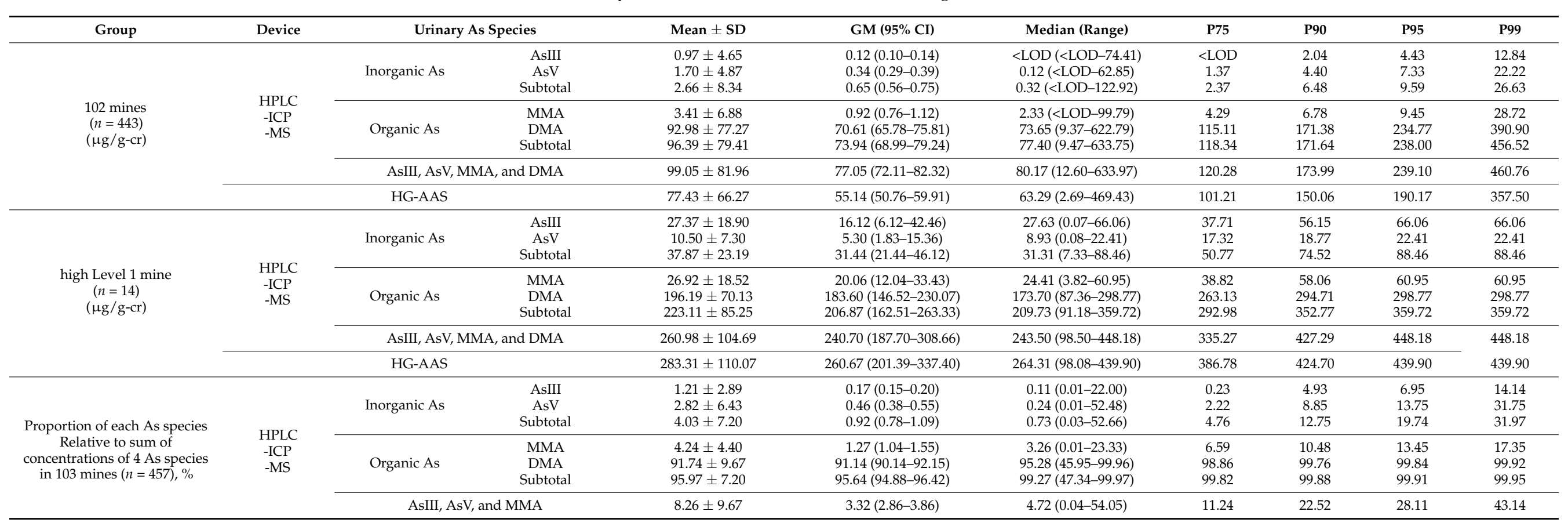

LOD: limit of detection; substitute $\mathrm{LOD} / 2$ value for all. $\mathrm{LOD}$ of $\mathrm{AsIII}=0.100 ; \mathrm{AsV}=0.164 ; \mathrm{MMA}=0.078 ; \mathrm{DMA}=0.022$. Urinary creatinine reference range: $0.3-3.0 \mathrm{~g} / \mathrm{L}$. 


\subsection{Agreement Between HG-AAS and HPLC-ICP-MS Arsenic Concentration Measurements}

Scatterplots and correlation coefficients were calculated to assess the correlation between HG-AAS and HPLC-ICP-MS in terms of UAL. The scatterplots showed a positive trend. The Pearson's correlation coefficient (r) and CCC were 0.902 and 0.868 , respectively (Figure 2a). When UALICP was an independent variable, the estimated simple linear regression model was $\mathrm{UAL}_{\mathrm{ICP}}=18.00+1.03 \times\left(\mathrm{UAL}_{\mathrm{AAS}}\right)$ and the slope of the regression was near unity and increased to the same level. However, the y-intercept was 18.00. Therefore, the average $\mathrm{UAL}_{\mathrm{ICP}}$ for each observation was $18 \mu \mathrm{g} / \mathrm{g}$-cr higher than that of $\mathrm{UAL}_{\mathrm{AAS}}$. $\mathrm{UAL}_{\mathrm{AAS}}=\mathrm{UAL}_{\mathrm{AAS}}+18.00$ was corrected to fit the reference line $\mathrm{UAL}_{\mathrm{ICP}}=1.00 \times\left(\mathrm{UAL}_{\mathrm{AAS}}\right)$. The $\mathrm{CCC}$ was adjusted to 0.894 , and the estimated regression equation was $\mathrm{UAL}_{\mathrm{ICP}}=-0.49 \pm 1.03 \times\left(\right.$ corrected $\left.\mathrm{UAL}_{\mathrm{AAS}}\right)($ Figure $2 b)$.

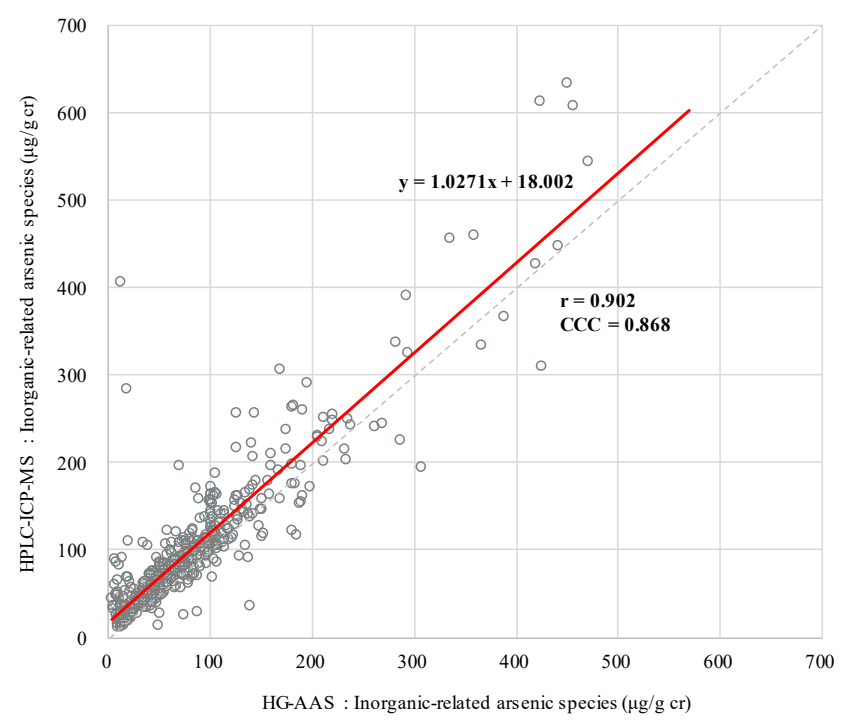

(a) Scatterplot of As concentration determined using two analytical methods.

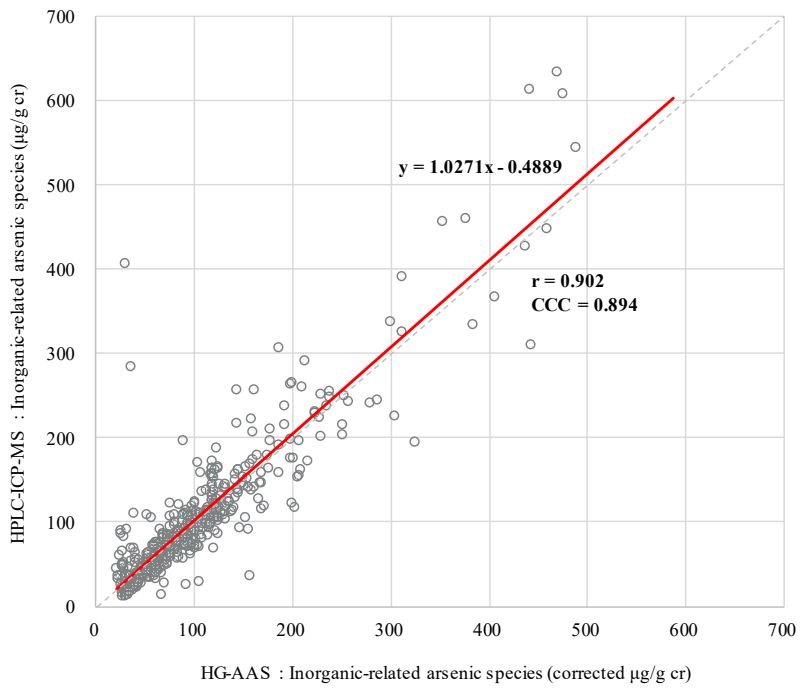

(b) Scatterplot of corrected As concentration determined using two analytical methods.

Figure 2. Scatterplots of As concentrations determined using HG-AAS and HPLC-ICP-MS in 103 abandoned metal mines.

\subsection{Proportions of Arsenic Species Concentrations}

The cAs proportions $(95 \% \mathrm{CI})$ were estimated by adjusting for sex, age, period of residence, drinking water, smoking status, and drinking status and compared to UAL $\mathrm{L}_{\mathrm{ICP}}$. Those of AsIII, AsV, MMA, and DMA were 0.79 (0.36-1.22)\%, 2.58 (1.62-3.53)\%, 4.33 (3.67-4.98)\%, and 92.31 (90.90-93.71)\%, respectively. The proportions of AsIII, AsV, iAs, MMA, and AsIII, $\mathrm{AsV}$, and MMA significantly increased with the numbers of males, children, and young adults, period of residence, no seafood intake in the last week, and decreasing distance from a mine. UAL ICP was divided by concentration into four quartiles (Q1-Q4). AsIII had a significantly higher concentration in $\mathrm{Q} 4$ than the others. In contrast, AsV and MMA had significantly higher concentrations in Q1 than the others (Table 2). To estimate cAs according to the $\mathrm{UAL}_{\mathrm{AAS}}$, the proportion of the average $\mathrm{cAs}$ for each percentile section of $\mathrm{UAL}_{\mathrm{ICP}}$ was used. A nonlinear model (proportion of $\mathrm{cAs}=\mathrm{f}\left(\mathrm{UAL}_{\mathrm{ICP}}\right)+\varepsilon$ ) was estimated for all four cAs and served as the coefficient of determination $\left(R^{2}\right)$. Assuming consistency between $\mathrm{UAL}_{\mathrm{ICP}}$ and $\mathrm{UAL}_{\mathrm{AAS}}$, the UAL for AsIII, AsV, and MMA was estimated by applying the model equation chosen according to the observed UAL AAS. DMA was evaluated according to the difference between UAL $\mathrm{AAS}_{\text {and }}$ the estimated AsIII, AsV, and MMA. To establish the goodness-of-fit of the cAs estimation model, we assessed the $R^{2}$ of the estimate for the actual observed cAs value. However, none of the values for AsIII, AsV, and MMA were satisfactory (Figure 3). 
Table 2. Adjusted proportions of as species concentration relative to the sum of the concentrations of 4 As species in 103 abandoned metal mines.

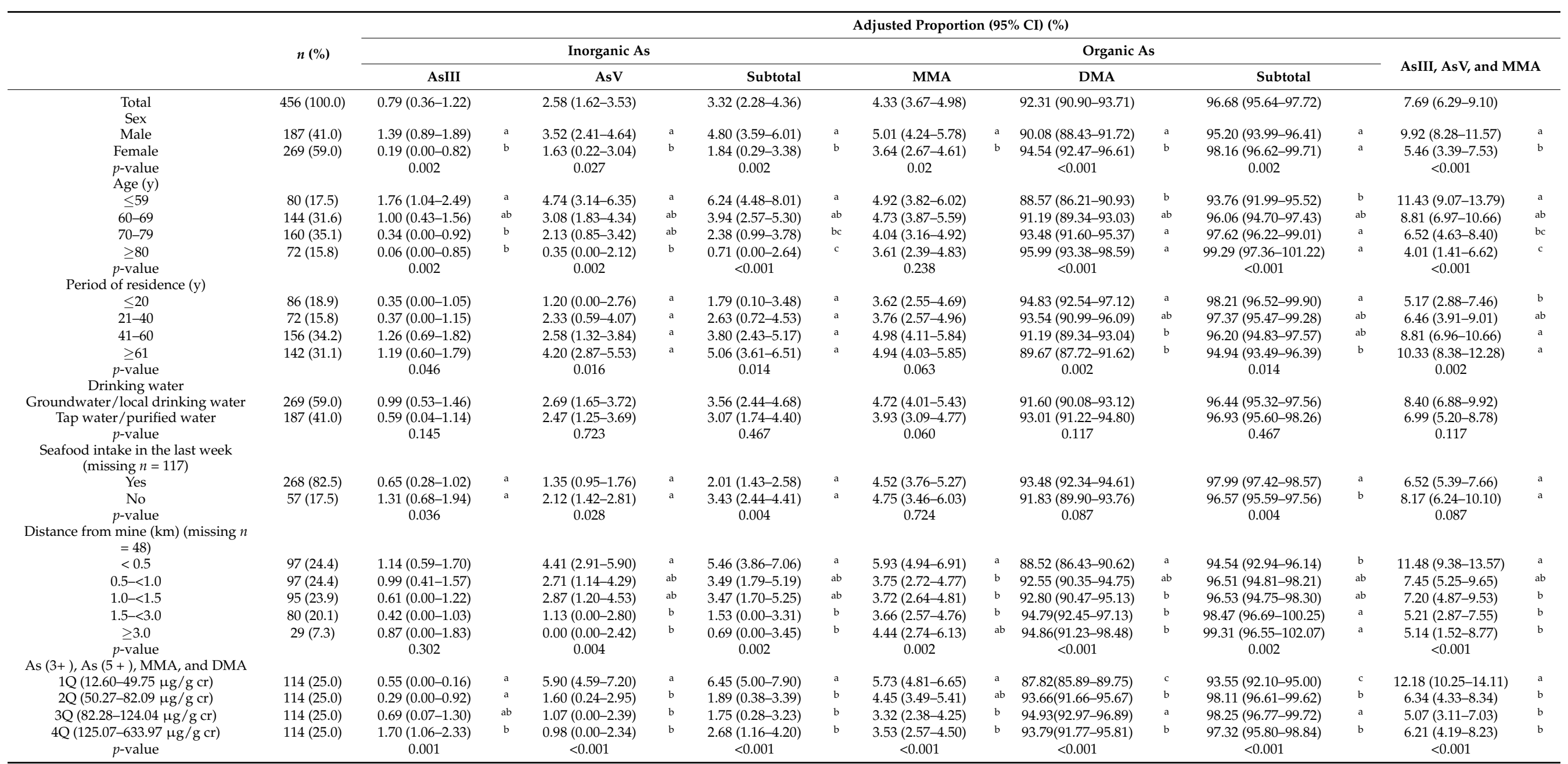

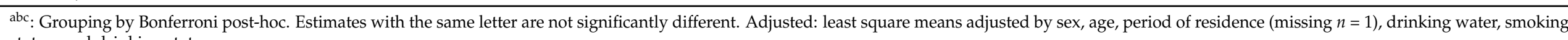
status, and drinking status. 


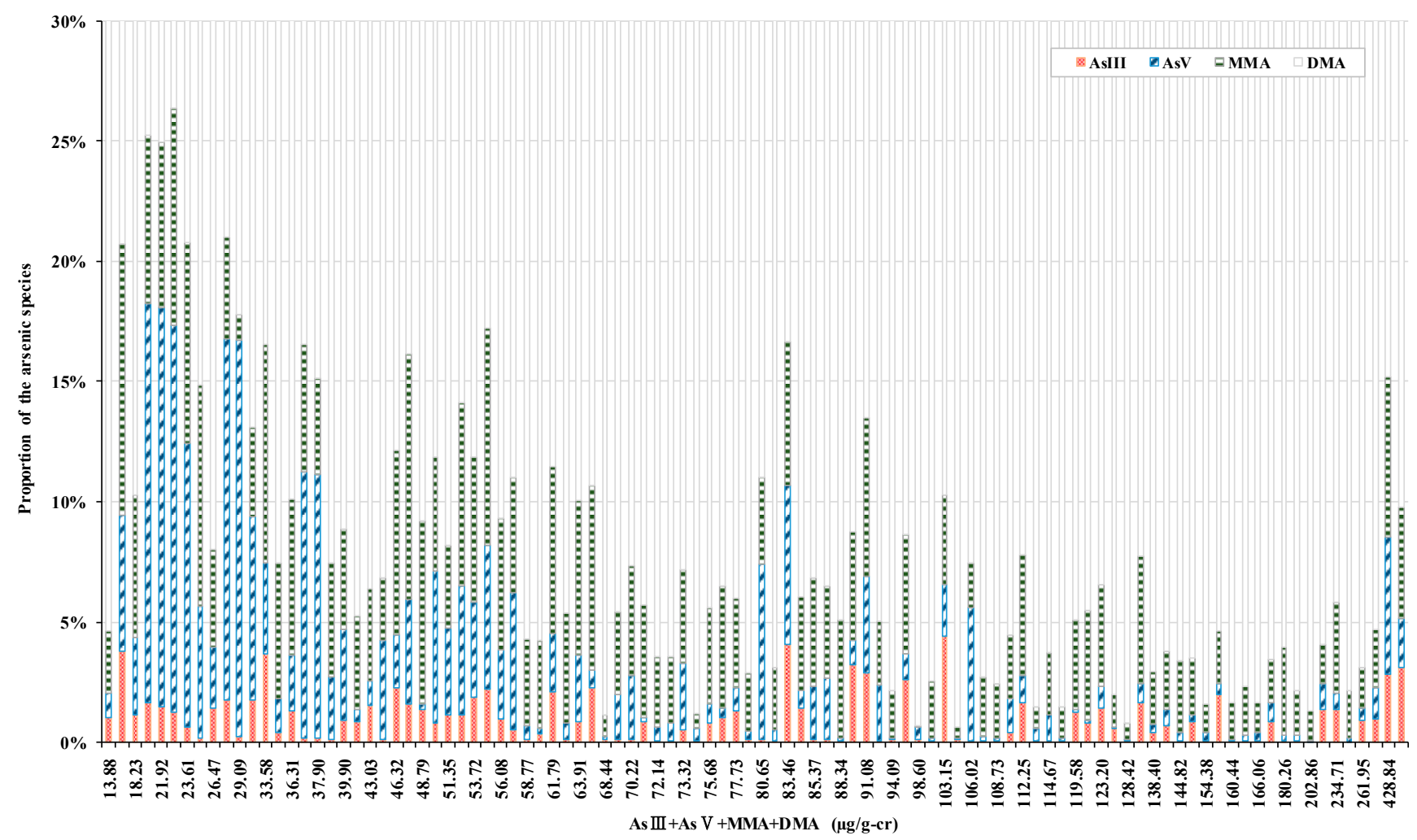

Figure 3. Proportion of As species relative to the sum of concentrations of four As species in 102 abandoned metal mines. Estimation of proportion of cAs using the simple nonlinear model (proportion of AsIII $(\%))=2.724 \times\left(1 /\left(\mathrm{hAs} \mathrm{s}^{0.529}\right)\right)$, $\mathrm{R}^{2}=0.104$; (proportion of AsV (\%)) $=0.0000998 \times \mathrm{hAs}^{2}-0.000603 \times \mathrm{hAs}+7.114$, adjusted $\mathrm{R}^{2}=0.273$; (proportion of MMA $(\%))=0.0000645 \times \mathrm{hAs}^{2}-0.0381 \times \mathrm{hAs}+6.773$, adjusted $\mathrm{R}^{2}=0.306$; (proportion of DMA $(\%))=-0.000184 \times \mathrm{hAs}^{2}+0.106 \times \mathrm{hAs}+84.716$, adjusted $\mathrm{R}^{2}=0.318$. Goodness-of-fit between cAs estimated by projecting hAs $s_{\text {AAS }}$ on the simple nonlinear model and actual observed cAs. Observed AsIII $=0.424 \times($ estimated AsIII $)-0.109$, $\mathrm{R}^{2}=0.0254$; observed $\mathrm{AsV}=-0.485 \times($ estimated $\mathrm{AsV})+2.413, \mathrm{R}^{2}=0.0233 ;$ observed MMA $=1.085 \times($ estimated MMA) $-0.00760, R^{2}=0.0432 ;$ observed DMA $=1.121 \times($ estimated DMA $)-7.165, R^{2}=0.843$

\section{Discussion}

Here, we used AMS data to show the characteristics of the cAs distribution and composition ratios in residents located near these sites. We observed consistency between the individual exposure assessment data determined using HPLC-ICP-MS and the hAs determined using HG-AAS.

The gold standard technique for evaluating As exposure is HPLC-hydride generationcoupled to inductively coupled plasma-mass spectrometry (HPLC-HG-ICP-MS). However, HG-AAS is a cost-effective alternative method for quantifying hAs, namely the sum of AsIII, AsV, MMA, and DMA [15]. This metric is used for As biomonitoring in Korea. Nevertheless, iAs toxicity differs from that of oAs. The cAs must be evaluated in areas where there is a high risk of iAs exposure. In the present study, the adjusted GM of the UAL of 102 mines in the AMS were 0.10, 0.31, 0.90, and $68.75 \mu \mathrm{g} / \mathrm{g}$-cr for AsIII, AsV, MMA, and DMA, respectively (Table S1). The 2015-2016 U.S. National Health and Nutrition Examination Survey (NHANES) showed that AsIII, AsV, and MMA were below their limits of detection (LOD) in $60 \%$ of all subjects and DMA was only $3.41 \mu \mathrm{g} / \mathrm{g}$-cr [16]. According to the 2008-2009 health statistics of the Korea National Health and Nutrition Examination Survey (KNHANES), the representative values of AsIII, AsV, MMA, and DMA in the general Korean population were $0.018,0.005,0.020$, and $11.013 \mu \mathrm{g} / \mathrm{g}$-cr, respectively [17]. Both the general population and those dwelling in vulnerable areas are exposed to iAs. The 
Korean population has the highest seafood consumption per capita $[18,19]$ and a relatively high DMA level. DMA occurs in certain algae and shellfish whose consumption may increase urinary DMA $[20,21]$. The iAs are 100 times more toxic than oAs. Among the iAs, AsIII is $\sim 60$ times more toxic than AsV [1]. In regions with a high seafood intake, the evaluation of human exposure via tAs and hAs artificially increases DMA. Hence, actual human exposure and health risk might be either exaggerated or underestimated, and human exposure should be evaluated through cAs.

$\mathrm{UAL}_{\mathrm{ICP}}$ was $\sim 18 \mu \mathrm{g} / \mathrm{g}$-cr higher than $\mathrm{UAL}_{\mathrm{AAS}}$. The estimate for the slope of the regression was $\sim 1.03$; the $\mathrm{r}$ and CCC were 0.902 and 0.868 , respectively; and the CCC of the corrected UAL $\mathrm{LAS}_{\mathrm{AS}}$ was 0.89 . Bühl et al. [15] showed consistency between the output of HG-AAS and HPLC-HG-ICP-MS for 40 samples. Their $r$ value was 0.971 , and their estimated regression model was $\mathrm{UAL}_{\mathrm{ICP}}=0.59+0.94 \times\left(\mathrm{UAL}_{\mathrm{AAS}}\right)$. Lindberg et al. [22] reported a regression model of $\mathrm{UAL}_{\mathrm{ICP}}=-5.19+1.02 \times\left(\mathrm{UAL}_{\mathrm{AAS}}\right)$ for 89 samples. Relative to $\mathrm{UAL}_{\mathrm{ICP}}=-0.49+1.03 \times\left(\right.$ corrected $\left.\mathrm{UAL}_{\mathrm{AAS}}\right)$ for the current study, it differed in terms of sample size and UAL range. However, the slopes were similar for both models. Therefore, high consistency and reliability may be achieved by adjusting for concentration differences between analytical methods.

The proportion of each cAs relative to UAL ICP was used to assess exposure trends. The proportion of DMA was $92.31 \%$, and the coefficient of the determination of DMA for UAL ICP was 0.958 . Thus, UAL ICP was strongly influenced by DMA. In contrast, high $\mathrm{UAL}_{\mathrm{ICP}}$ concentrations were not indicative of high AsV or MMA concentrations. Moreover, relatively high AsV and MMA concentrations were measured at low UAL ICP concentrations (Figure S1). The correlation coefficients of UAL ICP with AsV and MMA were -0.172 and -0.071 , respectively. Thus, they had an inverse linear relationship (Table S2). There was consistency between $\mathrm{UAL}_{\mathrm{ICP}}$ and $\mathrm{UAL}_{\mathrm{AAS}}$. For this reason, high AsV and MMA concentrations were not necessarily associated with high $\mathrm{UAL}_{\mathrm{AAS}}$ concentrations. KNIER [23] reported that HPLC-ICP-MS has low LOD and high analytical sensitivity and can detect lower element concentrations using fewer biological samples than HG-AAS. Furthermore, HPLC-ICP-MS can conduct multi-element analyses. However, cAs analysis is not cost-effective for large-scale biomonitoring. Consequently, $\mathrm{UAL}_{\mathrm{AAS}}$ has been used to select high-concentration exposure in AMS and to evaluate cAs [12]. However, the present study showed that UAL $\mathrm{LAS}_{\mathrm{A}}$ may have limited efficacy at screening for exposure to high iAs concentrations originating from environmental pollution sources. Therefore, exposure assessment through cAs, rather than $\mathrm{UAL}_{\mathrm{AAS}}$, is recommended for vulnerable areas where seafood consumption and human exposure risks of iAs are high. In particular, recently, a study was published that found a high possibility of As contamination on agricultural soils in abandoned metal mines in Korea [7]. This study assessed the interchangeability of cAs based on $\mathrm{UAL}_{\mathrm{AAS}}$ and established the unreliability of the estimated exponential and nonlinear second-order polynomial models. In other words, there is a tendency toward the UAL of cAs and the proportion of cAs according to UAL ICP. However, the estimated model introduces substantial calibration errors. UAL ICP could not isolate the causes for the change in highly toxic AsIII concentration. Therefore, cAs must be evaluated for vulnerable areas.

In the present study, exposure to relatively high $\mathrm{UAL}_{\mathrm{AAS}}$ concentrations was determined for residents living adjacent to 103 abandoned metal mine areas known to pose environmental and human health risks. We compared and evaluated human As exposure level from large-scale data and analyzed cAs. Here, we used large-scale data to simultaneously analyze both UAL AAS and cAs in 457 Korean samples. However, only those exposed to high $\mathrm{UAL}_{\mathrm{AAS}}$ concentrations in specific vulnerable areas were evaluated. For this reason, the validity of extrapolating these results to the general population is questionable. Evaluation agreement showed that the UAL $\mathrm{ICP}_{\mathrm{ICP}}$ level was higher than that of $\mathrm{UAL}_{\mathrm{AAS}}$. Moreover, the minimum value of $>18 \mu \mathrm{g} / \mathrm{g}$-cr obtained for the corrected $\mathrm{UAL}_{\mathrm{AAS}}$ was also a limitation. Nevertheless, the present study effectively assessed the consistency between two representative analytical methods for human As exposure and underscored the importance of evaluating cAs in vulnerable areas. 


\section{Conclusions}

Chronic exposure to low As concentrations was established for the contaminated areas studied here. A few areas presented with a risk of exposure to high As concentrations caused by polluted drinking water. However, as the Korean population has a high per capita seafood intake, the DMA exposure risk is also elevated. The evaluation of human exposure through tAs and hAs is associated with a high probability of exaggeration or underestimation because of the toxicity of these cAs. Hence, it is advised to assess exposure to highly toxic iAs through cAs. For this reason, cAs should be quantitated using HPLCICP-MS. There is reliable consistency between $\mathrm{UAL}_{\mathrm{ICP}}$ and $\mathrm{UAL}_{\mathrm{AAS}}$. A viable alternative is the estimation of iAs through interchangeable cAs and cost-effective AAS.

Supplementary Materials: The following are available online at https://www.mdpi.com/article/ 10.3390/toxics9060138/s1. Figure S1: Distribution of As species concentrations by AsIII, AsV, MMA, and DMA percentiles. Table S1: Adjusted geometric mean concentrations of As species in 102 abandoned metal mines. Table S2: Correlation coefficient of As species concentration and proportion.

Author Contributions: Conceptualization, writing-original draft preparation, and review and editing, J.-W.S.; supervision, Y.-S.H. All authors have read and agreed to the published version of the manuscript.

Funding: This research was funded by the Korea National Institute of Environmental Research.

Institutional Review Board Statement: The study was conducted according to the guidelines of the Declaration of Helsinki, and approved by the Institutional Review Board of Chung-Ang University (IRB No. 1041078-201805-HRBR-103-01, approved on 26 June 2018).

Informed Consent Statement: Informed consent was obtained from all subjects involved in the study.

Data Availability Statement: Restrictions apply to the availability of these data. Data were obtained from the Korea National Institute of Environmental Research and are available at https:/ /www. nier.go.kr/NIER/egovEngIndex.jsp (accessed on 3 March 2021) with the permission of the Korea National Institute of Environmental Research.

Acknowledgments: This study was supported by grants from the Environmental Health Center and National Institute of Environment Research (NIER) funded by the Ministry of Environment (MOE), Republic of Korea (NIER-2018-01-02-058).

Conflicts of Interest: The authors declare no conflict of interest.

\section{Abbreviation}

AM: arithmetic mean; AMS: The Health Effects Survey of Abandoned Metal Mines; As: arsenic; AsIII: arsenite; AsV: arsenate; ATSDR: Agency for Toxic Substances and Disease Registry; cAs: chemical species of arsenic; CCC: concordance correlation coefficient; CI: confidence interval; DMA: dimethylarsenic acid; GM: geometric mean; hAs: hazardous arsenic

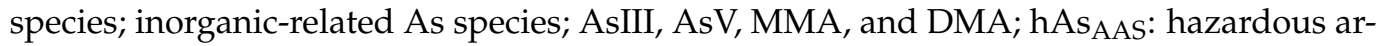
senic species concentration by hydride generation atomic absorption spectroscopy; $\mathrm{hAs}$ ICP: hazardous arsenic species concentration by high-performance liquid chromatography and inductively coupled plasma-mass spectrometry; HG-AAS: hydride generation atomic absorption spectroscopy; HPLC-ICP-MS: high-performance liquid chromatography and inductively coupled plasma-mass spectrometry; iAs: inorganic arsenic; KMOE: Korea Ministry of Environment; KNHAENS: Korea National Health and Nutrition Examination Survey; KNIRE: Korea National Institute of Environmental Research; LSMs: least square means; MMA: monomethylarsinic acid; NHANES: U.S. National Health and Nutrition Examination Survey; NPL: National Priorities List; oAs: organic arsenic; PLHS: priority list of hazardous substances; SD: standard deviation; tAs: total arsenic; UAL: urinary arsenic concentration; $\mathrm{UAL}_{\mathrm{AAS}}$ : urinary arsenic concentration by hydride generation atomic absorption spectroscopy; $\mathrm{UAL}_{\mathrm{ICP}}$ : urinary arsenic concentration by high-performance liquid chromatography and inductively coupled plasma-mass spectrometry. 


\section{References}

1. World Health Organization. Arsenic-Environmental Health Criteria 18; 9241540788; World Health Organization: Geneva, Switzerland, 1981

2. Roy, P.; Saha, A. Metabolism and toxicity of arsenic: A human carcinogen. Curr. Sci. 2002, 82, 38-45.

3. Lin, S.; Cullen, W.R.; Thomas, D.J. Methylarsenicals and arsinothiols are potent inhibitors of mouse liver thioredoxin reductase. Chem. Res. Toxicol. 1999, 12, 924-930. [CrossRef] [PubMed]

4. Petrick, J.S.; Ayala-Fierro, F.; Cullen, W.R.; Carter, D.E.; Vasken Aposhian, H. Monomethylarsonous acid (MMA(III)) is more toxic than arsenite in Chang human hepatocytes. Toxicol. Appl. Pharm. 2000, 163, 203-207. [CrossRef] [PubMed]

5. Chen, C.; Chiou, H.; Huang, W.; Chen, S.; Hsueh, Y.; Tseng, C.; Lin, L.; Shyu, M.; Lai, M. Systemic Non-Carcinogenic Effects and Developmental Toxicity of Inorganic Arsenic. In Arsenic Exposure and Health Effects; Chappell, W.R., Abernathy, C.O., Calderon, R.L., Eds.; Springer: London, UK, 1997; pp. 124-134.

6. World Health Organization. Arsenic and Arsenic Compounds. Environmental Health Criteria 224; 9241540788; World Health Organization: Geneva, Switzerland, 2001.

7. Yun, S.W.; Kang, D.H.; Ji, W.H.; Jung, M.H.; Yu, C. Distinct Dispersion of As, Cd, Pb, and Zn in Farmland Soils near Abandoned Mine Tailings: Field Observation Results in South Korea. J. Chem. 2020, 9671871. [CrossRef]

8. Farmer, J.G.; Johnson, L.R. Assessment of occupational exposure to inorganic arsenic based on urinary concentrations and speciation of arsenic. Br. J. Ind. Med. 1990, 47, 342-348. [CrossRef] [PubMed]

9. Martin, R.; Dowling, K.; Pearce, D.; Sillitoe, J.; Florentine, S. Health effects associated with inhalation of airborne arsenic arising from mining operations. Geosciences 2014, 4, 128-175. [CrossRef]

10. Deutsche Forschungsgemeinschaft. List of MAK and BAT values 2019. Permanent Senate Commission for the Investigation of Health Hazards of Chemical Compounds in the Work Area; Wiley-VCH Verlag GmbH: Weinheim, Germany, 2019.

11. US American Conference of Governmental Industrial Hygienists. TLVs and BEIs: Based on the Documentation of the Threshold Limit Values for Chemical Substances and Physical Agents and Biological Exposure Indices 2012; American Conference of Governmental Industrial Hygienist: Cincinnati, OH, USA, 2012.

12. Korea National Institute of Environmental Research. Environmental and Health Effects Survey of Residents around 2nd Phase Abandoned Metal Mines; Korea National Institute of Environmental Research: Incheon, Korea, 2017.

13. Korea National Institute of Environmental Research. KNEHS's Guide to Biological Sample Management(Revised); Korea National Institute of Environmental Research: Incheon, Korea, 2019.

14. Chung, J.Y.; Lim, H.J.; Kim, Y.J.; Song, K.H.; Kim, B.G.; Hong, Y.S. The separation of arsenic metabolites in urine by high performance liquid chromatographyinductively coupled plasma-mass spectrometry. Environ. Health Toxicol. 2014, 29 , e2014018. [CrossRef] [PubMed]

15. Bühl, V.; Álvarez, C.; Kordas, K.; Pistón, M.; Mañay, N. Development of a simple method for the determination of toxicologically relevant species of arsenic in urine using HG-AAS. J. Environ. Pollut. Hum. Health 2015, 3, 46-51. [CrossRef]

16. US Centers for Disease Control and Prevention. Fourth National Report on Human Exposure to Environmental Chemicals; Department of Health and Human Services, Centers for Disease Control and Prevention: Atlanta, GA, USA, 2019.

17. Korea Centers for Disease Control and Prevention. Korea Health Statistics: Korea National Health and Nutrition Examination Survey; Korea Centers for Disease Control and Prevention: Osong, Korea, 2017.

18. Guillen, J.; Natale, F.; Carvalho, N.; Casey, J.; Hofherr, J.; Druon, J.N.; Fiore, G.; Gibin, M.; Zanzi, A.; Martinsohn, J.T. Global seafood consumption footprint. Ambio 2019, 48, 111-122. [CrossRef] [PubMed]

19. Joint Research Centre. How Much Fish Do We Consume? First Global Seafood Consumption Footprint Published. Available online: https:/ / ec.europa.eu/jrc/en/news/how-much-fish-do-we-consume-first-global-seafood-consumption-footprintpublished (accessed on 28 August 2020).

20. Le, X.C.; Cullen, W.R.; Reimer, K.J. Human urinary arsenic excretion after one-time ingestion of seaweed, crab, and shrimp. Clin. Chem. 1994, 40, 617-624. [CrossRef] [PubMed]

21. Ma, M.; Le, X.C. Effect of arsenosugar ingestion on urinary arsenic speciation. Clin. Chem. 1998, 44, 539-550. [CrossRef] [PubMed]

22. Lindberg, A.L.; Goessler, W.; Grandér, M.; Nermell, B.; Vahter, M. Evaluation of the three most commonly used analytical methods for determination of inorganic arsenic and its metabolites in urine. Toxicol. Lett. 2007, 168, 310-318. [CrossRef] [PubMed]

23. Korea National Institute of Environmental Research. Establishment of Analytical Methods for Blood and Urine Using ICP/MS(II); Korea National Institute of Environmental Research: Incheon, Korea, 2009. 